BILIARY DISEASE

\title{
A prospective randomised study of "covered" versus "uncovered" diamond stents for the management of distal malignant biliary obstruction
}

\author{
H Isayama, Y Komatsu, T Tsujino, N Sasahira, K Hirano, N Toda, Y Nakai, N Yamamoto, M Tada, \\ H Yoshida, Y Shiratori, T Kawabe, M Omata
}

Gut 2004;53:729-734. doi: 10.1136/gut.2003.018945

See end of article for authors' affiliations

Correspondence to:

Dr H Isayama, Department

of Gastroenterology,

Faculty of Medicine,

University of Tokyo, 7-3-1

Hongo, Bunkyo-ku, Tokyo

113-8655, Japan;

isayama-2im@

h.u-tokyo.ac.jp

Accepted for publication 12 November 2003

\begin{abstract}
Background and aim: Covered self-expandable metal stents (EMS) were recently developed to overcome tumour ingrowth in conventional EMS. However, supporting evidence for the efficacy of covered EMS is lacking.

Patients and methods: We enrolled 112 patients with unresectable distal biliary malignancies. They were randomly assigned to polyurethane covered $(n=57)$ or original diamond stent $(n=55)$.

Results: Stent occlusion occurred in eight patients (14\%) after a mean of 304 days in the covered group, and in 21 patients (38\%) after a mean of 166 days in the uncovered group. The incidence of covered EMS occlusion was significantly lower than that of uncovered EMS ( $p=0.0032)$. The cumulative stent patency of covered stents was significantly higher than that of uncovered stents $(p=0.0066)$. No tumour ingrowth occurred in the covered group while it was observed in 15 patients in the uncovered group. In subgroup analysis, the cumulative patency of the covered EMS was significantly higher in pancreatic cancer $(p=0.0363)$ and metastatic lymph nodes $(p=0.0354)$. There was no significant difference in survival between the two groups. Acute cholecystitis was observed in two of the covered group and in none of the uncovered group. Mild pancreatitis occurred in five of the covered group and in one of the uncovered group.

Conclusions: Covered diamond stents successfully prevented tumour ingrowth and were significantly superior to uncovered stents for the treatment of patients with distal malignant biliary obstruction. However, careful attention must be paid to complications specific to covered self-expandable metal stents, such as acute cholecystitis and pancreatitis.
\end{abstract}

$P$ atients with malignant biliary obstruction generally have an unfavourable prognosis with a poor quality of life. Most biliary tumours are unresectable. Thus adequate palliative treatment for biliary obstruction is needed as prolongation of jaundice causes pruritus, malabsorption, and hepatocellular and renal dysfunction. Recanalisation of the obstructed bile duct is required.

Endoscopic or transhepatic stenting has become widely accepted as a standard procedure for the relief of jaundice in patients with malignant biliary obstruction. ${ }^{1}$ However, plastic tube stents often become occluded with sludge. Large bore plastic stents would appear to provide a solution ${ }^{2}$ but stent diameter is necessarily limited by the diameter of the accessory channel of the endoscope.

Self-expandable metallic stents (EMS) were introduced at the end of the 1980s to overcome the disadvantages of plastic stents. $^{3-5}$ EMS are held in an outer sheath of the delivery system, which is only $3.5-4 \mathrm{~mm}$ in diameter. They are expanded to 8-10 $\mathrm{mm}$ in the bile duct after release from the delivery system. Various studies showed that metallic stents have longer patency and lower occlusion rates compared with conventional plastic stents. ${ }^{6-10}$ However, tumours often invade the EMS via the mesh of the metallic wire, resulting in their obstruction. To protect against tumour ingrowth, EMS covered with a non-porous membrane were developed in the 1990s. ${ }^{11}$ However, data on the efficacy of covered EMS are limited and controversial. We also prospectively evaluated handcrafted polyurethane covered EMS for the treatment of neoplastic biliary obstruction, ${ }^{12}$ and found that covered EMS retained their patency much longer than uncovered ones.

However, the issue of covered versus uncovered EMS had yet to be subjected to a prospective randomised study, prompting us to conduct the present randomised controlled study.

\section{PATIENTS AND METHODS}

The present study was of a prospective randomised controlled design based on our pilot study. ${ }^{12}$ The study protocol was approved by the ethics committees of the participating institutes and performed at four affiliated hospitals according to the guidelines described in the Declaration of Helsinki for biomedical research involving human subjects. Participating endoscopists had considerable experience carrying out biliary interventions (each at least five years; approximately 250 cases per year).

\section{Eligibility criteria}

Patients were consecutively enrolled into the study on their initial diagnosis of unresectable malignant biliary obstruction. Neoplasms were diagnosed based on pathological examination or clinical and imaging findings. We determined the staging of neoplasms based on the findings of computed tomography and endoscopic ultrasonography. The definition of unresectable was made after consultation with the surgeon and anaesthesiologist. Exclusion criteria were defined previously, based on the status of biliary obstruction disease, such as hilar obstruction, and a value of $<3$ in performance status according to the scales of the Eastern Cooperative Oncology Group. ${ }^{13}$

Abbreviations: EMS, self-expandable metallic stents; ERCP, endoscopic retrograde cholangiopancreatography 


\section{Randomisation}

Patients were registered by telephone with one author (YS, at Tokyo University Hospital as the registration centre). The randomisation procedure was stratified on disease groupspancreatic cancer, bile duct cancer, metastatic nodes, and other malignancies, including gall bladder cancer, papillary cancer, and others-by computer generated random numbers.

\section{Covered stent}

A self-expandable Ultraflex Diamond Stent (Microvasive; Boston Scientific Corporation, Natik, Massachusetts, USA) with a partial polyurethane cover was used in this study (fig 1). This stent was handcrafted by the first author (HI), as previously described. ${ }^{12}$ Polyether-type polyurethane was used as the covering material because of its resistance to hydrolysis compared with other types of polyurethane in general. $^{14} 15$

\section{Insertion of the stent}

Plastic tube stents or nasobiliary drainage tubes were placed endoscopically at initial endoscopic retrograde cholangiopancreatography (ERCP) after the papilla was dilated with endoscopic papillary balloon dilation, as previously described, ${ }^{16-19}$ or was managed with sphincterotomy.

After determining the unresectability of the neoplasms, patients were randomly assigned to the covered or uncovered EMS group. The plastic tube stents or nasobiliary drainage tubes were replaced with either covered or uncovered diamond stents under fluoroscopic guidance using a therapeutic duodenal endoscope (TJF-200; Olympus, Tokyo, Japan).

When endoscopic drainage of the bile duct was unsuccessful, we adopted the percutaneous transhepatic approach under ultrasonic and fluoroscopic guidance. Covered or uncovered EMS were inserted either percutaneously or via the endoscopic route using the combined endoscopicpercutaneous procedure. $^{20}$

When we performed ERCP, we focused on the patency of the cystic duct. Cases interpreted as impossible were referred to magnetic resonance cholangiopancreatography, computed tomography, and endoscopic ultrasonography, based on the fact that we had experience of cholecystitis occurring in patients with incomplete malignant obstruction of the cystic duct after inserting covered EMS. ${ }^{12}$

\section{Follow up and definition of end points}

Blood biochemistry, clinical signs, and symptoms were monitored on an outpatient basis. Stent occlusion was diagnosed when patients presented with jaundice, cholangitis, or cholestasis. Palliative intervention through either endoscopic or percutaneous drainage was performed as soon as possible, and the causes of stent obstruction were

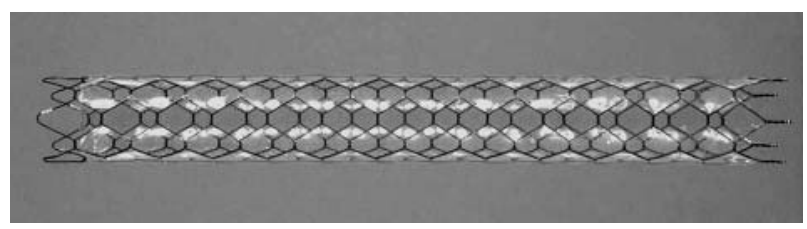

Figure 1 Covered diamond stent (Microvasive; Boston Scientific Corporation, Natik, Massachusetts, USA). The stents used in this study were $10 \mathrm{~mm}$ in width and 60 or $80 \mathrm{~mm}$ in length, with the length determined on the basis that the covered portion should be at least $20 \mathrm{~mm}$ longer than the stenotic lesion. The stent was partially covered with polyurethane. The thickness of the covered membrane was 50-60 $\mu \mathrm{m}$. The stents were left uncovered for $5 \mathrm{~mm}$ from both ends to prevent their migration or movement. investigated by cholangioscopic examination. The end points of this study were stent obstruction or patient death.

\section{Cost effectiveness}

The costs of initial stent placement and re-intervention were calculated. The price of the uncovered diamond stent was US\$2560 in Japan. The cost for covering was calculated as US\$100.

\section{Statistical analysis}

Our previous study showed an occlusion rate for covered EMS of $14 \%,{ }^{12}$ approximately $20 \%$ less than that of uncovered EMS (33\%) reported by Davids and colleagues. ${ }^{6}$ For a 5\% type I error with $80 \%$ statistical power, the required number of patients in each group was estimated to be 77 .

The stent patency period was calculated as the interval between stent insertion and its obstruction or death with a patent stent. Cumulative stent patency and patient survival were estimated by the Kaplan-Meier technique and supplemented by the log rank test for comparisons between groups. ${ }^{21}$ For analysis of stent patency, patients without stent obstruction were censored at the time of analysis. The MannWhitney $U$ test was used for comparison of quantitative variables and Fisher's exact test for qualitative variables. All analysis was done with statistical software (Statview, version 5.0; SAS Institute Inc., Cary, North Carolina, USA). ${ }^{22}$

We planned an interim analysis when the number of eligible patients reached 50 cases in each group. This analysis assessed the feasibility and tolerance of treatment. We used the Pocock group sequential method for interim monitoring so that we could stop the entry of a patient into this study soon after the between group difference in cumulative patency according to Kaplan-Meier analysis reached significance. ${ }^{23}$

\section{RESULTS}

\section{Patient enrolment and characteristics}

A total of 115 were consecutively enrolled between August 1998 and August 2001 at the first interim analysis. Three patients were excluded; one patient died from a cardiac event before the metallic stent placement and two rejected the EMS insertion after their enrolment.

The remaining 112 patients were followed until November 2002. Clinical features were similar between the two groups, as shown in table 1 . No patient was lost during the follow up period.

\section{Stent insertion and drainage}

The initial drainage and stent insertion were performed endoscopically or percutaneous-transhepatically without any procedure related complications (table 1). EMS were placed successfully with sufficient drainage in all patients.

\section{Early term complications}

Complications occurring within 30 days after EMS placement were considered "early". No stent obstruction occurred after insertion in the covered EMS group while EMS were occluded in four cases in the uncovered EMS group. The stents of three had tumour tissue invasion whereas in the fourth the cause of obstruction, occurring within 24 hours but recanalising spontaneously three days after insertion, was unknown.

Excluding four patients who had undergone cholecystectomy previously, acute cholecystitis occurred in two of 42 patients $(4.8 \%)$ who had overlapped cystic duct orifice in the covered group. This complication did not occur in any of the 52 patients in the uncovered group. Both patients with acute cholecystitis had tumour invasion to the cystic duct, as demonstrated by initial cholangiograms. Both underwent percutaneous gall bladder drainage and improved rapidly. 


\begin{tabular}{|lcc|}
\hline \multicolumn{2}{|c|}{ Table 1 Patient characteristics } & \\
\hline & Covered EMS & Uncovered EMS \\
\hline No of patients & 57 & 55 \\
Sex (M/F) & $35 / 22$ & $31 / 24$ \\
Age (y) (mean (range)) & $70.5(48-88)$ & $70.4(40-89)$ \\
Primary tumour size (mm) (mean (SD)) & $40.3(14.3)$ & $41.0(16.0)$ \\
Length of stricture (mm) (mean (SD)) & $31.1(12.8)$ & $29.0(10.4)$ \\
Diagnosis & & \\
Pancreas cancer & 34 & 32 \\
Bile duct cancer & 6 & 5 \\
Metastatic nodes & 12 & 11 \\
Gall bladder cancer & 3 & 6 \\
Papillary cancer & 2 & 1 \\
Pathological diagnosis & $43(75 \%)$ & $38(69 \%)$ \\
Reason for unresectable & $48(84 \%)$ & $48(87 \%)$ \\
Advanced cancer & $8(14 \%)$ & $6(11 \%)$ \\
Advanced age & $1(2 \%)$ & $1(2 \%)$ \\
Other & $10.5(7.2)$ & $8.5(6.3)$ \\
Bilirubin (mg/dl) (mean (SD)) & $1578(976)$ & $1359(1054)$ \\
ALP (IU/I) (mean (SD)) & & \\
Procedure for initial drainage & 41 & 42 \\
Endoscopic & 16 & 13 \\
Transhepatic & & \\
Procedure for stent insertion & 45 & 50 \\
Endoscopic & 5 \\
(Combined technique) & $(4)$ & \\
Transhepatic & 12 & \\
\hline EMS, expandable metallic stent; ALP, alkaline phosphatase. & \\
No significant differences between the two groups. & & \\
\hline
\end{tabular}

There were eight patients with tumour invasion to the cystic duct and overlapped orifice in the covered group. Among those patients, a high incidence $(2 / 8 ; 25 \%)$ of acute cholangitis was seen. However, there was no cholecystitis in patients with a patent cystic duct.

Five patients $(8.7 \%)$ in the covered group and one $(1.8 \%)$ in the uncovered group suffered from mild pancreatitis. All recovered with conservative treatment. There were no significant differences in the complication rate of acute pancreatitis between the covered and uncovered groups. All six patients improved with conservative treatment, including a mean 4.2 day fast (range $2-8$ days).

Biliary bleeding due to pseudoaneurysm of the pancreatic arcade occurred in two pancreatic cancer patients in the uncovered group. Blood transfusion was required in both cases. Transcatheter arterial embolisation was performed with metallic coil in one case while the coeliac and supermesenteric arteries were invaded and a covered EMS was inserted to compress the aneurysm in the other. Those patients required no more blood transfusion but the latter patient suffered from recurrent small amounts of bleeding and cholangitis, and died 49 days after insertion.

\section{Survival and late complications}

The mean follow up period after EMS insertion was 246 days (range 11-1155). At the time of evaluation, 104 patients $(93 \%)$ had died-52 (91\%) in the covered group (pancreatic cancer $32(94 \%)$, bile duct cancer six $(100 \%)$, metastatic nodes $11(92 \%)$, gall bladder cancer two $(67 \%)$, papillary cancer one $(50 \%))$ and $52(95 \%)$ in the uncovered group (pancreatic cancer $30(94 \%)$, bile duct cancer four $(80 \%)$, metastatic nodes $11(100 \%)$, gall bladder cancer six (100\%), papillary cancer one $(100 \%))$.

There was no significant difference in overall patient survival (fig 2), with mean survival being 255 days in the covered group and 237 days in the uncovered group.

Cumulative stent patency according to the Kaplan-Meier lifetime table was significantly higher $(p=0.0066)$ in the covered group than in the uncovered group (fig 3). Patency rates in the covered and uncovered groups were $100 \%$ and $81 \%$ after three months, $91 \%$ and $68 \%$ after six months, and $74 \%$ and 55\% after 12 months, respectively. Stent occlusion, including cases within 30 days after stent insertion, occurred in eight patients (14\%) after a mean of 304 days in the covered group and in 21 patients (38\%) after a mean of 161 days in the uncovered group. The incidence of covered EMS occlusion was significantly lower than that of uncovered EMS $(p=0.0354)$. The causes of stent obstruction are summarised in table 2 . No tumour ingrowth occurred in the covered group while it was observed in $16(29 \%)$ of the uncovered group. Tumour overgrowth was observed in both groups. Two obstructed covered stents due to biliary sludge were removed endoscopically using a snare and replaced with a new covered stent. There was one crushed stent case in the covered group 421 days after stent insertion. This patient with pancreatic cancer demonstrated a crushed metallic stent on $x$ ray and presented with jaundice. The crushed stent was removed endoscopically and was replaced with a new covered EMS.

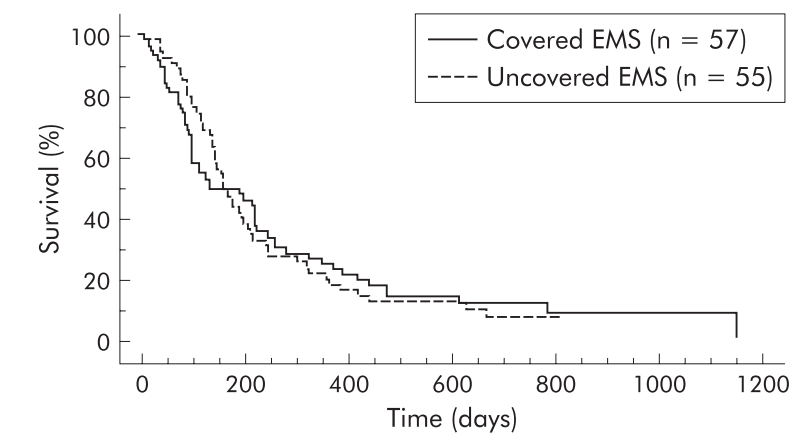

Covered EMS

$\begin{array}{lllllllllllll}\text { No at risk } & 38 & 27 & 16 & 12 & 8 & 6 & 4 & 2 & 2 & 1 & 1 & 0\end{array}$

$\begin{array}{lllllllllllll}\text { Survival } & 67 & 47 & 28 & 21 & 14 & 14 & 12 & 9 & 9 & 9 & 9 & 9\end{array}$

Uncovered EMS

$\begin{array}{llllllllll}\text { No at risk } & 43 & 22 & 15 & 9 & 7 & 5 & 3 & 1 & 0\end{array}$

$\begin{array}{llllllllll}\text { Survival } & 78 & 40 & 27 & 16 & 13 & 13 & 8 & 8 & 8\end{array}$

Figure 2 Kaplan-Meier graph showing survival of the patients. No significant difference was observed between the covered and uncovered groups. EMS, self-expandable metallic stents. 


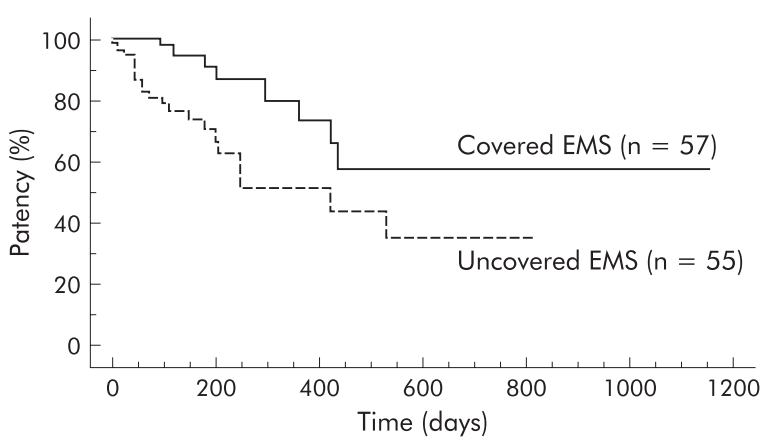

Covered EMS

$\begin{array}{lllllllllllll}\text { No at risk } & 37 & 23 & 12 & 10 & 5 & 4 & 3 & 2 & 2 & 1 & 1 & 0\end{array}$ $\begin{array}{lllllllllllll}\text { Patency } & 98 & 87 & 80 & 74 & 58 & 58 & 58 & 58 & 58 & 58 & 58 & 58\end{array}$

Uncovered EMS

$\begin{array}{llllllllll}\text { No at risk } & 37 & 17 & 9 & 7 & 6 & 3 & 2 & 1 & 0\end{array}$

$\begin{array}{llllllllll}\text { Patency } & 79 & 67 & 52 & 52 & 44 & 35 & 35 & 35 & 35\end{array}$

Figure 3 Kaplan-Meier graph showing cumulative patency. Stent patency was significantly higher $(p=0.0066)$ in the covered group than in the uncovered group. EMS, self-expandable metallic stents.

The cumulative patency of covered EMS was significantly higher than that of uncovered EMS in pancreatic cancer $(\mathrm{p}=0.0363)$ (fig 4$)$. In patients with locally advanced pancreatic cancer (19 in the covered and 24 in the uncovered group), it was also significantly higher $(\mathrm{p}=0.0401)$. In cases of pancreatic cancer with metastasis (16 in the covered and eight in the uncovered group) however there was no significant difference in cumulative stent patency between the two groups. Higher patency was also observed in biliary obstruction due to metastatic lymph nodes $(p=0.0354)$ (fig 5$)$. There were no significant differences in patients with bile duct cancer and those with other diseases, including gall bladder cancer and papillary cancer.

Inward stent migration was observed 83 days after stent placement in one patient in the covered group who manifested mild cholangitis but had apparent stent patency. An additional covered EMS was put in place and it remained patent until the patient's death (123 days).

\section{Cost effectiveness}

The mean number of re-interventions for relief of stent failures and complications was significantly lower

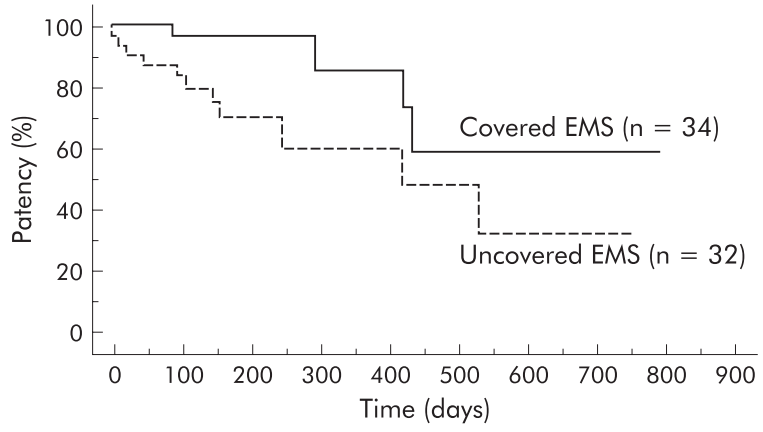

Covered EMS

$\begin{array}{lcccccccc}\text { No at risk } & 24 & 15 & 8 & 7 & 2 & 2 & 1 & 0 \\ \text { Patency } & 96 & 96 & 86 & 86 & 59 & 59 & 59 & 59\end{array}$

Uncovered EMS

$\begin{array}{lllllllll}\text { No at risk } & 23 & 9 & 6 & 5 & 4 & 2 & 1 & 0\end{array}$

$\begin{array}{lllllllll}\text { Patency } & 84 & 71 & 61 & 61 & 49 & 32 & 32 & 32\end{array}$

Figure 4 Kaplan-Meier graph showing cumulative patency in patients with pancreatic cancer. Stent patency was significantly higher $(p=0.0363)$ in the covered group than in the uncovered group. EMS, self-expandable metallic stents.

$(p=0.023)$ in the covered group $(0.32(0.78))$ compared with the uncovered group $(0.72(1.04))$. Mean total cost for treatment including initial stent placement and re-intervention in the covered group (US\$3901.3 (1636.0)) was significantly $(\mathrm{p}=0.0072)$ lower than that in the uncovered group (US\$5129.1 (2950.6)).

\section{Autopsy findings}

Postmortem examination was performed in 19 patients (nine in the covered and 10 in the uncovered group). Tumour ingrowth was not observed in the covered group. Small amounts of sludge at the inside of stents were found in all covered cases. One patient with pancreatic cancer had stent obstruction due to duodenal invasion. All covered EMS examined had not embedded into the bile duct wall and could be removed easily.

In the uncovered group, tumour ingrowth was observed in all 10 patients, including patients without symptoms related to stent obstruction. Sludge was also observed in all patients, with greater volumes than in the covered group.

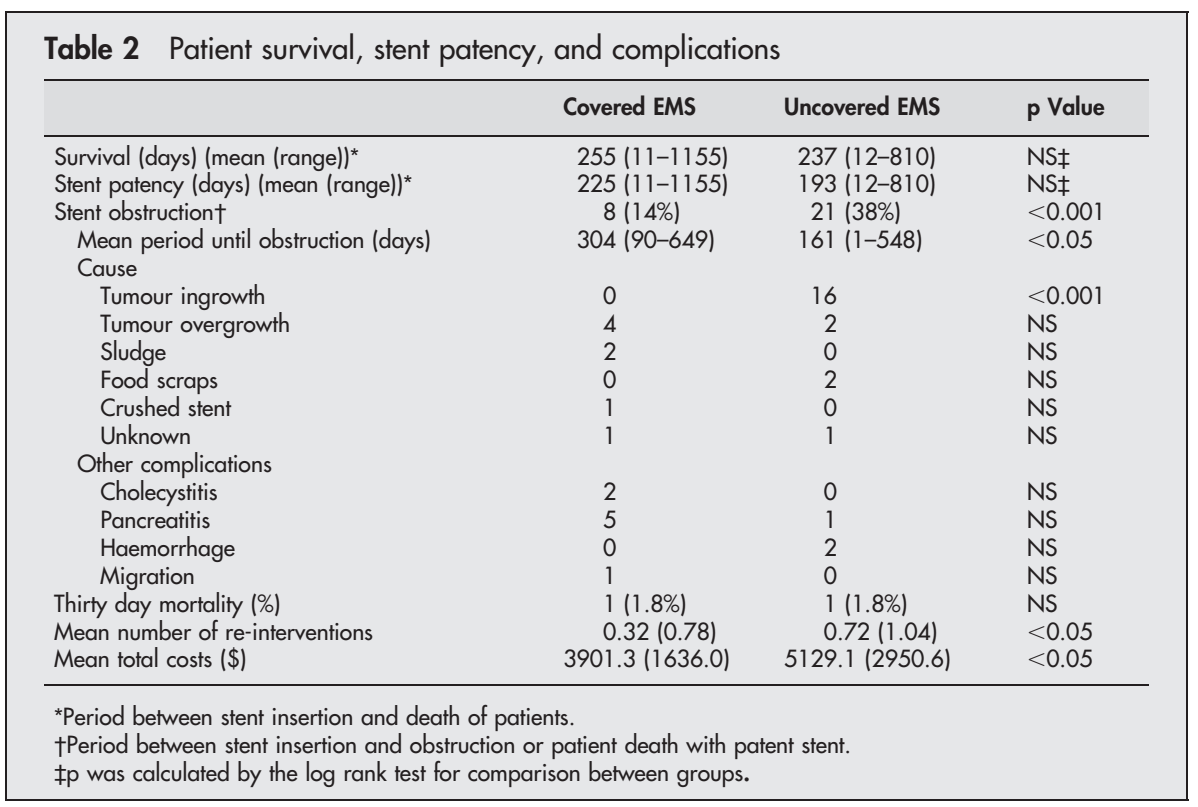




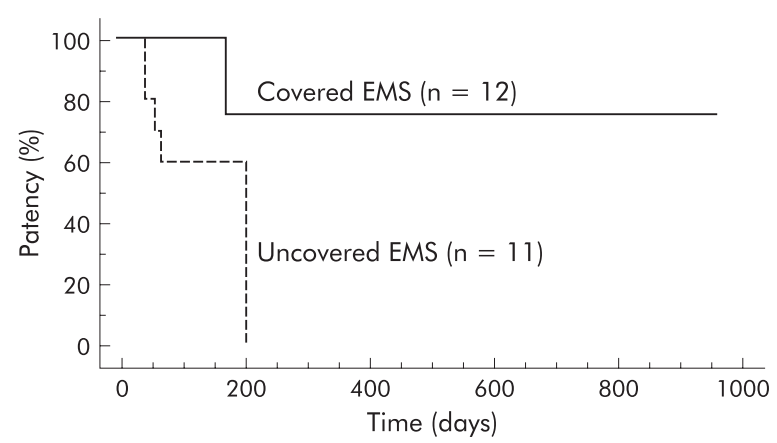

Covered EMS

$\begin{array}{lccccccccc}\text { No at risk } & 5 & 2 & 1 & 1 & 1 & 1 & 1 & 1 & 0 \\ \text { Patency } & 100 & 75 & 75 & 75 & 75 & 75 & 75 & 75 & 75\end{array}$

Uncovered EMS

$\begin{array}{llll}\text { No at risk } & 5 & 2 & 0\end{array}$

Patency $\quad 56 \quad 56 \quad 0$

Figure 5 Kaplan-Meier graph showing cumulative patency in patients with metastatic lymph nodes. Stent patency was significantly higher $(p=0.0354)$ in the covered group than in the uncovered group. EMS, self-expandable metallic stents.

Stent occlusion was observed in four patients (three pancreatic cancer and one bile duct cancer). Of these, three underwent covered EMS insertion as stent in stent, and tumour ingrowth was not observed in these additional covered EMS.

\section{DISCUSSION}

Covered EMS were first developed in 1994 in Japan. ${ }^{11}$ Subsequently, Gore-Tex, ${ }^{11}$ silicone, ${ }^{24}$ and polyurethane ${ }^{25-30}$ were evaluated as materials for the covered membrane. Miyayama et al, using polyurethane covered Gianturco stents, reported that the stent occlusion rate was only $5 \%$ due to tumour overgrowth above the stent edge and that no tumour ingrowth was observed. ${ }^{26}$ However, other studies suggested that a covering membrane was not effective in preventing tumour ingrowth and did not improve stent patency. ${ }^{27-29}$ Hausegger et al, using polyurethane covered Wallstents, reported that the obstruction rate of those covered EMS was 33\%, mainly due to tumour ingrowth, concluding that covered EMS were not superior to uncovered EMS. ${ }^{29}$

More recently, we published a prospective consecutive study using handmade polyurethane covered Wallstents. ${ }^{12}$ Mean periods of survival and stent patency were 233 days and 206 days, respectively. Tumour ingrowth was not observed although a small amount of tumour had invaded via a pinhole in the membrane into the lumen of EMS in one case. We used a membrane of $40-50 \mu \mathrm{m}$ in thickness in that study while those used in the other studies were $15 \mu \mathrm{m}$ thick. ${ }^{27-29}$ We were convinced that covered EMS could overcome tumour ingrowth if the membrane was of sufficient thickness. Therefore, we conducted the present study with membranes of 50-60 $\mu \mathrm{m}$ thick.

Our study showed significantly higher cumulative stent patency with covered than with uncovered EMS. In the covered group, there was no tumour ingrowth while stent obstruction caused by tumour ingrowth was observed in 16 (29\%) patients in the uncovered group. Covered EMS were successful in preventing tumour ingrowth. This protective effect was also confirmed by the postmortem examinations. In nine covered cases of 19 undergoing autopsy, no tumour ingrowth was found, whereas it was observed in all 10 uncovered cases, including patients without symptoms of stent occlusion.
However, stent occlusion was observed in eight patients in the covered group in the present study. The cause of occlusion was tumour overgrowth in four, sludge in two, crushed in one, and unknown in one. In all four cases with stent obstruction by tumour overgrowth, neoplastic tissue extensively invaded to the hepatic hilum or the duodenum (data not shown). In our previous study, we observed two cases with stent obstruction by tumour overgrowth. Those obstructions could be prevented by the use of a longer covered EMS. ${ }^{12}{ }^{31}$ Therefore, we paid careful attention to the length of the stents in the present study. Despite these considerations however, occlusion from overgrowth was observed, suggesting that it may be difficult to prevent this type of obstruction completely. The crushed metallic stent was removed endoscopically and we thought that the cover would stay durable. However, the wire and cover had broken when it was removed and we could not confirm our suggestion.

Removal of covered stents was easily performed in three patients in the present series while it was impossible or extremely difficult to remove uncovered stents whose wire meshes were embedded in the tumour tissue. This advantage suggests a novel use for covered stents as temporally endoprostheses. Thus we may expand the indications of metal stents

Stent patency and patient survival may differ according to the causative disease. Thus subgroup analysis was also performed. The cumulative patency of covered EMS was significantly higher in patients with pancreatic cancer and metastatic nodes. However, there were no differences in pancreatic cancer with distant metastasis as the prognosis of these patients was too short to allow evaluation of the efficacy of covered EMS. In patients with bile duct cancer or other diseases, no significant differences were seen between the covered and uncovered groups. Their number was limited in the present study, and further studies with larger numbers are needed to evaluate the efficacy of covered EMS in these diseases.

Covered EMS overcame tumour ingrowth, and stent patency was improved. However, cholecystitis occurred in $4.2 \%$ as a complication particular to covered EMS. This complication was frequently observed in patients with tumour invasion to the cystic duct, when its orifice was overlapped by the covered EMS. Careful attention must be paid to the possible occurrence of this complication on insertion of the covered EMS for such cases or, alternatively, the use of an uncovered EMS might be considered. However, this complication was not observed in patients who had a patent cystic duct even if the orifice was overlapped. Mild acute pancreatitis occurred in $8.7 \%$ of the covered and $1.8 \%$ of the uncovered group. No significant differences were observed between the covered and uncovered groups. However, this may have been due to a limited number of patients. We should also direct careful attention to patients whose orifice of the main pancreatic duct is overlapped.

Stent migration is another complication that mostly involves covered EMS. However, no well documented studies have been published. This complication occurred in only one patient in the present study and was not observed in 21 patients undergoing placement of covered EMS in our previous study. ${ }^{12}$ Hence stent migration does not appear to occur frequently.

Biliary bleeding due to pseudoaneurysm occurred in two patients in the uncovered group; this condition was not observed in the covered group. A covering membrane may have the potential to prevent bleeding by compression of pseudoaneurysm, if any.

In the present study, there were no significant differences in survival rate between the covered and uncovered groups. 
We performed appropriate procedures immediately when the stents became occluded. If we had not, survival of those patients may have been much shorter. However, the present data clearly suggest that covered stents overcome tumour ingrowth and reduce the rate of stent occlusion. Furthermore, the covered metal stent significantly reduced the number of re-interventions. It may contribute to improvement in quality of life of patients. Consequently, the total cost was also significantly smaller in the covered group. In the present analysis however, the cost of additional metal stents for re-intervention was included. If metal stents are not employed for re-intervention, the total costs would be lower by US $\$ 2660$. Even then, the total cost was significantly lower in the covered than in the uncovered group (US\$3622.5 (971.4) $v$ US $\$ 4168.5$ (1607.7); $\mathrm{p}=0.0311$ ).

We used diamond stents as EMS in the present study while Wallstents were used in our previous study. ${ }^{12}$ Diamond stents are easier to handle in terms of making more durable covered stents than Wallstents. Although many studies have been performed in evaluating the efficacy of these stents, it remains controversial as to which stent is superior. ${ }^{32}{ }^{33}$ The efficacy by "cover" may be different due to the type of metallic stent. The efficacy of this stent should be evaluated in comparison with covered diamond stents, although handcrafted covered Wallstents in our previous study showed a similar efficacy to that of covered diamond stents in the present study.

In conclusion, covered diamond stents were significantly superior to uncovered diamond stents in terms of patency for the treatment of patients with distal biliary malignant obstruction. However, caution must be exercised regarding complications specific to covered EMS, such as acute cholecystitis or pancreatitis, but these were not significantly higher in our study. There was no significantly difference in patient survival. However, the number of re-interventions in relation to the patient's quality of life and cost effectiveness in the covered group were significantly superior to those in the uncovered group. There is a need for further studies to determine whether covered metallic stents are superior to other types of uncovered metallic stents or metallic stents covered with another material.

\section{ACKNOWLEDGMENTS}

We gratefully acknowledge the assistance of Chikuma Hamada, PhD, Department of Pharmacoepidemiology, Rokurou Miyazawa, Department of Medical Photography, University of Tokyo, Hisashi Yamada, MD, Ryou Nakata, MD, Masashi Ihori, MD, Yoshikazu Maruyama, MD, Toru Isoyama, MD, Japanese Red Cross Medical Center, Kazumi Tagawa, MD, Makoto Taniguchi, MD, Mitsui Memorial Hospital, and Tetsurou Katamoto, MD, JR Tokyo General Hospital.

\section{Authors' affiliations \\ H Isayama, Y Komatsu, N Sasahira, K Hirano, N Toda, Y Nakai, N Yamamoto, M Tada, H Yoshida, Y Shiratori, Department of Gastroenterology, University of Tokyo, Tokyo, Japan}

T Tsujino, Department of Gastroenterology, Japanese Red Cross Medical Center, Tokyo, Japan

T Kawabe, Department of Endoscopy and Endoscopic Surgery, Faculty of Medicine, University of Tokyo, Tokyo, Japan

M Omata, Department of Gastroenterology, and Department of

Endoscopy and Endoscopic Surgery, University of Tokyo, Tokyo, Japan

\section{REFERENCES}

1 Smith AG, Dowset JF, Rassell RCG, et al. Randomized trial of endoscopic stenting versus surgical bypass in malignant low bileduct obstruction. Lancet $1994 ; 344: 1655-60$
2 Speer AG, Cotton PB, MacRae KD. Endoscopic management of malignant biliary obstruction: stents of 10 French gauge are preferable to stents of 8 French gauge. Gastrointest Endosc 1988;34:412-17

3 Irving JD, Adam AD, Dick R, et al. Gianturco expandable metallic biliary stents: results of a European clinical trial. Radiology 1989;172:321-6.

4 Huibregtse K, Cheng J, Coene PPLO, et al. Endoscopic placement of expandable metal stents for biliary strictures: a preliminary report on experience with 33 patients. Endoscopy 1989;21:280-2.

5 Lammer J, Klein GE, Kleinert R, et al. Obstructive jaundice: use of expandable metal endoprosthesis for biliary drainage. Radiology 1990;177:789-92.

6 Davids PHP, Groen AK, Rauws EAJ, et al. Randomized trial of self-expanding metal stents versus polyethylene stents for distal malignant biliary obstruction. Lancet 1992;340:1488-92.

7 Knyrim K, Wagner HJ, Pausch J, et al. A prospective, randomized, controlled trial of metal stents for malignant obstruction of the common bile duct. Endoscopy 1993;25:207-12.

8 Lammer J, Hausegger KA, Flükiger F, et al. Common bile duct obstruction due to malignancy: Treatment with plastic versus metal stents. Radiology 1996;201:167-72.

9 Prat F, Chapat O, Ducot B, et al. A randomized trial of endoscopic drainage methods for inoperable malignant strictures of the common bile duct. Gastrointest Endosc 1998;47:1-7.

10 Hoepffner N, Foerster EC, Högemann B, et al. Long-term experience in Wallstent therapy for malignant choledochal stenosis. Endoscopy 1994;26:597-602

11 Saito H, Sakurai Y, Takamura A, et al. Biliary endoprosthesis using Gore-Tex covered expandable metallic stents: Preliminary clinical evaluation. Nippon Acta Radiologica 1994:54:180-2.

12 Isayama H, Komatsu Y, Tsujino T, et al. Polyurethane-covered metal stent for management of distal malignant biliary obstruction. Gastrointest Endosc 2002:55:366-70.

13 WHO handbook for reporting results of cancer treatment. Geneva: World Health Organization, 1979

14 Pavlova M, Doraganova M. Hydrolytic stability of polyurethane medical adhesive dressing. Biomaterials 1994;15:59-62.

15 Edwards A, Carson RJ, Szycher M, et al. In vitro and invivo biodurability of a compliant microporous vascular graft. J Biomaert Appl 1998;13:23-45.

16 Komatsu Y, Kawabe T, Toda N, et al. Endoscopic papillary balloon dilation for the management of common bile duct stones: experience of 226 cases. Endoscopy 1998;30:12-17.

17 Kawabe T, Komatsu Y, Tada M, et al. Endoscopic papillary balloon dilation in cirrhotic patients: removal of common bile duct stones without sphincterotomy. Endoscopy 1996;28:694-8.

18 Bergman JJGHM, Rauws EAJ, Fockens P, et al. Randomised trial of endoscopic balloon dilation versus endoscopic sphincterotomy for removal of bile duct stones. Lancet 1997:349:1124-9.

19 MacMathuna P, White P, Clarke E, et al. Endoscopic balloon sphincteroplasty (papillary dilation) for bile duct stones: efficacy, safety, and follow-up in 100 patients. Gastrointest Endosc 1995;42:468-74.

20 Dowsett JF, Vaira D, Hatfield AR, et al. Endoscopic biliary therapy using the combined endoscopic and percutaneous technique. Gastroenterology 1989;96:1180-6.

21 Peto R, Pike MC, Armitage P, et al. Design and analysis of randomized clinical trials requiring prolonged observation of each patient $I I$. Br J Cancer 1977;35:1-39.

22 StatView for Windows, Version 5.0. Stat Methods Med Res 1999:8:337-41.

23 Pocock SJ. Group sequential methods in the design and analysis of clinical trials. Biometrika 1977;64:191-7.

24 Silvis SE, Sievert CE, Vennes JA, et al. Comparison of covered versus uncovered wire mesh stents in the canine biliary tract. Gastrointest Endosc 1994:40:17-21.

25 Thurnher SA, Lammer J, Thurnher MM, et al. Covered self-expanding transhepatic biliary stents: Clinical pilot study. Cardiovasc Intervent Radiol 1996:19:10-14.

26 Miyayama S, Matsui O, Terayama N, et al. Covered Gianturco stent for malignant biliary obstruction: Preliminary clinical evaluation. J Vasc Interv Radiol 1997;8:641-8.

27 Rossi P, Bezzi M, Salvatori FM, et al. Clinical experience with covered Wallstents for biliary malignancies: 23-month follow-up. Cardiovasc Intervent Radiol 1997:20:441-7.

28 Born P, Neuhaus H, Rösch T, et al. Initial experience with a new, partially covered Wallstent for malignant biliary obstruction. Endoscopy 1996;28:699-702

29 Hausegger KA, Thurnher S, Bordendöfer G, et al. Treatment of malignant biliary obstruction with polyurethane-covered Wallstents. AJR Am J Roentgenol 1998; 170:403-8.

30 Kawase Y, Motoyama A, Kawanishi M, et al. Experience with Strecker stent covered with polyurethane membrane for malignant biliary strictures. Gastroenterol Endosc 1995:37:1229-35.

31 Bezzi M, Orsi F, Salvatori FM, et al. Selfexpandable nitinol stent for the management of biliary obstruction: Long-term clinical results. J Vasc Interv Radiol 1994:5:287-93.

32 Dumonceau JM, Cremer M, Auroux J, et al. A comparison of Ultraflex Diamond Stents and Wallstents for palliation of distal malignant biliary strictures. Am J Gastroenterol 2000;95:670-6.

33 Ahmad J, Siqueira E, Martin J, et al. Effectiveness of the Ultraflex Diamond stent for the palliation of malignant biliary obstruction. Endoscopy 2002;34:793-6. 